\title{
ARAÚJO, Ana Valéria (Org.). Povos Indígenas e a Lei dos Brancos: o direito à diferença. Brasília: MEC/SECAD; LACED/Museu Nacional, 2006. 212p. (Coleção Educação Para Todos. Série Vias dos Saberes n. 3).
}

ESTELLA LIBARDI SOUZA ${ }^{1}$

$U F P A$

TIAGO AUGUSTO DA SILVA VENTURA ${ }^{2}$

$U F P A$

Para falar sobre o livro Povos Indígenas e a Lei dos Brancos: o direito à diferença, organizado, e em boa parte escrito, por Ana Valéria Araújo, é necessário considerar, em primeiro lugar, a finalidade da publicação, qual seja: fornecer subsídios à formação de estudantes indígenas de nível superior, como nos esclarece o prefácio.

Terceiro volume da série de livros Vias dos Saberes, desenvolvida pelo Projeto Trilhas de Conhecimentos: o Ensino Superior de Indígenas no Brasil, do Laboratório de Pesquisas em Etnicidade, Cultura e Desenvolvimento (LACED), ligado ao Museu Nacional da Universidade Federal do Rio de Janeiro, essa coleção destina-se, sobretudo, aos estudantes indígenas em cursos de graduação no Brasil, e seus textos

\begin{abstract}
visam agregar à experiência de cada um pontos de partida para a composição dos instrumentos necessários para aguçar a percepção quanto aos amplos desafios à sua frente, diante de metas que têm sido formuladas por seus povos, suas organizações e comunidades (ARAÚJO, 2006, p. 11).
\end{abstract}

\footnotetext{
${ }^{1}$ Graduanda em Direito na Universidade Federal do Pará (UFPA). Bolsista de Iniciação Científica do CNPq. E-mail: estellalibardi@gmail.com .

${ }^{2}$ Graduando em Direito na Universidade Federal do Pará (UFPA). Bolsista de Iniciação Científica do CNPq. E-mail: tiaguinho.ventura@gmail.com .
} 
SOUZA e VENTURA - Povos indígenas e a lei dos brancos...

Revela-se, assim, o caráter "instrumental" da série, isto é, seus textos pretendem funcionar como "instrumentos políticos" na promoção (e não mero reconhecimento) da diversidade sociocultural. E, se estamos falando de "lutas políticas", o objetivo da publicação nos indica quem são os atores políticos que devem travá-las: os próprios povos indígenas, compreendidos aqui como sujeitos históricos, "atores" (e não "vítimas") de sua própria história, como propôs Manuela Carneiro da Cunha (1992).

O "protagonismo indígena" na defesa de seus direitos e interesses - como nos informa Gersem dos Santos Luciano, índio da etnia Baniwa, antropólogo e autor de outro volume da série ${ }^{3}$ - fortaleceu-se no Brasil desde a década de 70 , quando se deu o surgimento e consolidação do movimento indígena organizado, num processo de luta, mobilização e pressão dos índios que resultou na conquista histórica dos direitos indígenas na Constituição Federal de 1988, que afirmou os povos indígenas como "... protagonistas, sujeitos coletivos e sujeitos de direitos e de cidadania brasileira e planetária" (LUCIANO, 2006, p. 19).

É nesse contexto que a publicação do livro organizado por Ana Valéria Araújo se insere. Araújo (2006) traz a discussão sobre os direitos indígenas no Brasil propondo “... uma análise não apenas dos direitos específicos estabelecidos pelo ordenamento jurídico, mas também uma reflexão comparativa a partir dos direitos garantidos a todos os brasileiros" (ARAÚJO, 2006, p. 17).

As duas primeiras partes, escritas por Ana Valéria Araújo, pretendem situar o debate sobre os direitos indígenas, traçando um panorama histórico do reconhecimento desses direitos e fazendo uma análise do direito indígena aplicado.

Na primeira parte, Araújo (2006) oferece uma evolução histórica dos direitos dos povos indígenas no Brasil. A autora mostra como

[o]s direitos dos povos indígenas, hoje fundamentados na Constituição Brasileira, foram sendo conquistados e amadurecidos no curso de uma história nem sempre justa ou generosa, que, por muito tempo, sequer permitiu aos índios se fazerem ouvir (ARAÚJO, 2006, p. 24).

\footnotetext{
${ }^{3}$ Vide resenha publicada nesta edição.
} 
Do período colonial, no qual "... simplesmente não se cogitava dar aos conquistado nenhum direito”, (ARAÚJO, 2006, p. 24) e da política tutelar (já no período republicano) que pretendia integrar os índios à sociedade "nacional", assimilando-os, chegamos à Constituição de 1988. Resultado da intensa mobilização indígena durante o processo constituinte, a Carta de 1988 representa, segundo a autora, um marco divisor para a avaliação da situação dos índios hoje, uma vez que de desde sua promulgação houve um avanço significativo na proteção e no reconhecimento dos direitos dos povos indígenas no país. Nas palavras de Araújo,

o diploma constitucional quebrou o paradigma da integração e da assimilação que até então dominava o nosso ordenamento jurídico, assegurando aos índios o direito à diferença, calcado na existência de diferenças culturais, e garantindo aos povos indígenas permanecerem como tal, se assim o desejarem, devendo o Estado assegurar-Ihes as condições para que isso ocorra (ARAÚJO, 2006, p. 45).

Na segunda parte do livro, Araújo (2006) apresenta o "estado da arte" em relação aos direitos dos povos indígenas. Essa tarefa pressupõe não apenas discutir os marcos legais em que o debate sobre esses direitos se situa (a CF/88, Código Civil, Estatuto do Índio, Convênio 169) como também a aplicação prática e efetividade de tais direitos no cenário brasileiro. Para Araújo (2006), embora a Constituição Federal tenha revolucionado os padrões de relacionamento dos povos indígenas com o Estado brasileiro, quebrando premissas e superando preconceitos até então arraigados em nosso ordenamento jurídico, os índios ainda estão distantes até mesmo do pleno gozo dos direitos a eles já garantidos.

Ao tratar da "lei dos brancos", o objetivo do livro é instrumentalizá-la pelos (e a favor dos) povos indígenas no Brasil. Não é por acaso, portanto, que os autores da obra - com exceção da própria Ana Valéria Araújo, que é uma advogada "branca" - são todos advogados indígenas (ou "indígenas advogados", como talvez prefiram). Os ensaios autorais escritos por eles, que integram a terceira parte do livro, são todos, em boa medida, resultado não apenas da "reflexão" em torno dos direitos indígenas, mas da "atuação" pessoal de cada um 
deles na defesa desses direitos. São idéias e experiências de como utilizar a "lei dos brancos" na defesa dos direitos indígenas.

Joênia Batista de Carvalho é Wapixana e advogada, e tem trabalhado especialmente na defesa dos direitos territoriais indígenas, como atuação destacada na luta pela demarcação da Terra Indígena Raposa Serra do Sol. No ensaio Terras Indígenas: a casa é um asilo inviolável, aponta os avanços trazidos pela Constituição de 1988 no que se refere aos direitos territoriais indígenas (como o "indigenato", que reconhece o direito originário dos povos indígenas aos seus territórios ocupados tradicionalmente, e a inviabilidade do domicilio, que a autora defende que seja aplicado em relação às terras indígenas), destaca a relação dificultosa entre propriedade indígena e propriedade privada, e afirma a necessidade de luta para que esses direitos sejam garantidos de fato, com a efetiva proteção do Estado.

Paulo Celso de Oliveira é Pankararu e advogado, e atuou, por exemplo, no Instituto Socioambiental, além de ter experiência advogando para povos e comunidades indígenas. Seu ensaio é $O$ direito ao meio ambiente ecologicamente equilibrado e os direitos indígenas, no qual trabalha as relações construídas entre o direito dos povos indígenas e o direito ambiental. Paulo Pankararu destaca os conflitos que vêm ocorrendo entre o direito ambiental e o direito indígena, principalmente no que tange à sobreposição de unidades de conservação e terras indígenas, não obstante os povos indígenas sempre tenham elaborado formas de desenvolvimento que contribuem para a preservação do meio ambiente. Para o autor, tais conflitos devem ser resolvidos com base no principio da razoabilidade, uma vez que a legislação ambiental vem se constituindo como importante instrumento de defesa dos direitos e dos interesses dos povos indígenas, indicando que há uma relação profícua entre os direitos indígenas e o direito ao meio ambiente.

Lucia Fernanda Jóef é Kaingang e advogada, e entre outras experiências profissionais, é membro-fundador do Núcleo de Advogados Indígenas do Instituto Indígena Brasileiro para a Propriedade Intelectual (INBRAPI). Parte dessa experiência revela-se no ensaio $A$ proteção legal do patrimônio cultural dos Povos Indígenas no Brasil, no qual procura sistematizar alguns instrumentos jurídicos existentes, a 
nível nacional e internacional, que tratem da utilização do patrimônio cultural dos povos indígenas, apontando as principais dificuldades na aplicação dos mecanismos de proteção da propriedade intelectual dos povos indígenas (como o não reconhecimento da natureza coletiva desse patrimônio e a dificuldade de sua valoração econômica). Destaca também questões ignoradas na aplicação prática do ordenamento jurídico vigente, o que leva à necessidade de criar um sistema especifico de proteção, baseado na transdisciplinariedade, no respeito e no reconhecimento da diversidade cultural e jurídica de cada povo indígena.

Vilmar Martins Moura Guarany é Mbya Guarani e advogado. Exerceu o cargo de coordenador geral de defesa dos direitos indígenas da FUNAI e integrou grupos de trabalho sobre direitos indígenas na ONU e OEA. No ensaio, Desafios e perspectivas para a construção e o exercício da cidadania indígenas, trata de alguns aspectos relativos à nacionalidade indígena e à atual legislação sobre a temática. Vilmar Guarany destaca o modo como os índios são reconhecidos pelas diferentes legislações brasileiras e pelas políticas públicas que possuem recorte étnico e são implementadas pelo Estado. $\mathrm{O}$ autor problematiza a questão da cidadania indígena, expondo alguns entraves cotidianos ao seu exercício.

James J. Lenoir - ou S. James Anaya, como é conhecido - é o advogado e professor de leis e política de direitos humanos da Faculdade de Direito da Universidade do Arizona. Leciona e é autor de diversas obras nas áreas dos direitos humanos internacionais, do direito constitucional e dos direitos dos povos indígenas. Trabalhou como advogado em defesa dos povos indígenas americanos e minorias, e já representou povos indígenas perante organizações e tribunais internacionais. Em Os Direitos Humanos dos Povos Indígenas, James Anaya aprofunda algumas reflexões em relação à legislação e a jurisprudência internacional sobre direitos indígenas, destacando a Convenção 169 da OIT como o instrumento mais concreto de expressão dos direitos indígenas, e que vêm dando impulso para que sejam 
SOUZA e VENTURA - Povos indígenas e a lei dos brancos...

publicadas declarações a respeito dos direitos indígenas no âmbito da $\mathrm{ONU}^{4}$ e da OEA.

Vê-se, portanto, que os advogados indígenas autores desta obra possuem em comum ampla experiência na luta pelos direitos de seus povos e, ao tratarem da "lei dos brancos", ampliam essa luta para uma área estratégica. Ao mesmo tempo, trazem novas perspectivas para o "Direito branco", uma vez que os advogados indígenas,

aportando as visões próprias daqueles que foram treinados para operar o ordenamento político brasileiro, .... são portadores também da singular experiência de vida de serem integrantes autóctones das Américas (ARAúJO, 2006, p. 14).

Vista sob esse prisma, é possível perceber a importância da formação jurídica para povos indígenas, na medida em que a posse desse conhecimento permite-lhes, como fazem os autores desta obra, operar por dentro da "lei branca", utilizando-se de seus instrumentos, mas a partir de suas sensibilidades jurídicas peculiares ${ }^{5}$ para dar efetividade àquilo que conquistaram a duras penas na Constituição de 1988. Permitem revelar, sobretudo, as dificuldades de se lidar com um ordenamento que, - como afirma Antonio Carlos de Souza Lima (2006), no prefácio - apesar da (tensa) presença dos direitos indígenas, (ainda) permanece (ou se acredita) único, mas que, desde 1988, pretende (e tem por obrigação) ser sensível à diversidade.

\section{Referências bibliográficas}

ARAÚJO, Ana Valéria (Org.). Povos Indígenas e a Lei dos Brancos: o direito à diferença. Brasília: MEC/SECAD; LACED/Museu Nacional, 2006. 212p. (Coleção Educação Para Todos. Série Vias dos Saberes n. 3). Disponível em: http://unesdoc.unesco.org/images/0015/001545/154567POR.pdf . Acesso em: 26 out. 2008.

\footnotetext{
${ }^{4}$ Em 13 de setembro de 2007, foi aprovada pela Assembléia Geral da Organização das Nações Unidas (ONU), a Declaração dos Direitos dos Povos Indígenas, tendo o Brasil como país signatário.

${ }^{5}$ De acordo com Clifford Geertz, as sensibilidades jurídicas referem-se aos significados emanados do campo jurídico-legal; traduzem conceito(s) de justiça específico(s), sentido(s) de Direitos particular(es) a cada cultura, variando conforme o saber local (GEERTZ, 1998).
} 
SOUZA e VENTURA - Povos indígenas e a lei dos brancos...

CARNEIRO DA CUNHA, Manuela. "Introdução a uma história indígena". In:

(Org.). História dos índios no Brasil. São Paulo: Cia. das letras, 1992.

GEERTZ, Clifford. O Saber Local. Petrópolis: Vozes, 1998.

LIMA, Antonio Carlos de. Prefácio - nas trilhas das universidades: direito indígena e os direitos dos índios no Brasil. In: ARAÚJO, Ana Valéria (Org.). Povos Indígenas e a Lei dos Brancos: o direito à diferença. Brasília: MEC/SECAD; LACED/Museu Nacional, 2006. p. 11-15. (Coleção Educação Para Todos. Série Vias dos Saberes n. 3). Disponível em: http://unesdoc.unesco.org/images/0015/001545/154567POR.pdf . Acesso em: 26 out. 2008.

LUCIANO, Gersem dos Santos. O índio brasileiro: o que você precisa saber sobre os povos indígenas no Brasil de hoje. Brasília: MEC/SECAD; LACED/Museu Nacional, 2006. 233p. (Coleção Educação Para Todos. Série Vias dos Saberes n. 1). Disponível em: http://unesdoc.unesco.org/images/0015/001545/154565por.pdf . Acesso em: 26 out. 2008. 